\title{
Relationship between Physical Activity and Cardiovascular Risk Factors: A Cross-Sectional Study among Low-Income Housewives in Kuala Lumpur
}

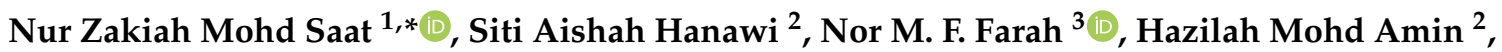 \\ Hazlenah Hanafiah ${ }^{4}$ and Nur Shazana Shamsulkamar ${ }^{1}$ \\ 1 Biomedical Science Programme, Centre of Community Health (ReaCH), Faculty of Health Sciences, \\ Universiti Kebangsaan Malaysia, Kuala Lumpur 50300, Malaysia; shazana2497@gmail.com \\ 2 SOFTAM, Faculty of Information Science and Technology, Universiti Kebangsaan Malaysia, Bangi 43600 \\ Malaysia; ctaishah@ukm.edu.my (S.A.H.); hazilah@ukm.edu.my (H.M.A.) \\ 3 Occupational Therapy Programme, Centre of Community Health ( $\mathrm{ReaCH})$, Faculty of Health Sciences, \\ Universiti Kebangsaan Malaysia, Kuala Lumpur 50300, Malaysia; norfarah@ukm.edu.my \\ 4 Faculty of Computer and Mathematical Science, Universiti Teknologi MARA Sabah Branch, \\ Kota Kinabalu Campus, Sabah 88997, Malaysia; hazlenahh@uitm.edu.my \\ * Correspondence: nurza@ukm.edu.my; Tel.: +60-39-289-7606
}

check for updates

Citation: Mohd Saat, N.Z.; Hanawi, S.A.; M. F. Farah, N.; Mohd Amin, H.; Hanafiah, H.; Shamsulkamar, N.S. Relationship between Physical Activity and Cardiovascular Risk Factors: A Cross-Sectional Study among Low-Income Housewives in Kuala Lumpur. Int. J. Environ. Res. Public Health 2021, 18, 6090. https:// doi.org/10.3390/ijerph18116090

Academic Editor: Paul B. Tchounwou

Received: 22 April 2021

Accepted: 31 May 2021

Published: 4 June 2021

Publisher's Note: MDPI stays neutral with regard to jurisdictional claims in published maps and institutional affiliations.

Copyright: (c) 2021 by the authors. Licensee MDPI, Basel, Switzerland. This article is an open access article distributed under the terms and conditions of the Creative Commons Attribution (CC BY) license (https:// creativecommons.org/licenses/by/ $4.0 /)$
Abstract: Cardiovascular disease is a significant public health concern worldwide, including in Malaysia. Various attempts have been made to resolve this issue. One of the most important methods of controlling cardiovascular risk factors is physical exercise. However, today's women, especially housewives, are often identified by a lack of physical activity. This is alarming to society, as cardiovascular disease can affect the quality of their life. The aim of this study is to determine the relationship between physical activity and cardiovascular risk factors among low-income housewives in Kuala Lumpur. A total of 63 housewives participated in this cross-sectional study. All participating housewives were asked to fill out a sociodemographic questionnaire and the short version of the International Physical Activity Questionnaire (IPAQ). To evaluate cardiovascular risk factors, anthropometric measurements and blood samples were taken. Findings showed that an average of $70.5 \pm 232.4 \mathrm{~min} /$ week was spent on moderate-to-vigorous physical activity (MVPA), which indicated a low level of physical activity. Data showed that $90.5 \%$ of the subjects had low physical activity, $6.3 \%$ were moderate, and $3.2 \%$ were considered as having a high level of physical activity. For body mass index (BMI), 58.7\% of the respondents were obese, $28.6 \%$ were overweight $\left(29.10 \pm 5.67 \mathrm{~kg} \mathrm{~m}^{-2}\right)$, and $81.0 \%$ of subjects had a waist circumference (WC) value above the normal range $(92.74 \pm 16.40 \mathrm{~cm})$. A two-way ANOVA test revealed significant mean differences between systolic blood pressure $(\mathrm{mm} / \mathrm{Hg})$ and age groups $(p>0.05)$. Nevertheless, there was a significant association between MVPA and cardiovascular risk factors using negative binomial regression $(p<0.01)$. The findings of this study highlight the need for health promotional programs to raise awareness, educate, and engage low-income housewives in lifestyle-enhancing behaviors.

Keywords: cardiovascular risk factors; physical activity; housewives; obesity and overweight

\section{Introduction}

Cardiovascular disease (CVD), which is also known as heart disease, is the dominant contributor to death worldwide and a prime contributor in reducing the quality of life of an individual [1]. According to the World Health Organization (WHO, Geneva, Switzerland), cardiovascular disease, especially heart attacks and strokes, were reported in 2016 as major contributors to the increasing mortality rate in the world, where $31 \%$ of the global mortality rate was due to this disease [2]. This is also a threat in Malaysia, where the highest percentage of deaths in Malaysia was recorded due to cardiovascular disease, at $35 \%$ [3]. 
Several causes, including metabolic factors such as hyperglycemia, hypertension, obese or overweight, and hypercholesterolemia, all contribute to the progression of this cardiovascular disease. Furthermore, environmental factors (lack of physical exercise, heavy alcohol consumption, smoking habits, and an unhealthy diet) contribute to the disease prevalence $[4,5]$. As a result, several public health authorities are focusing on these risk factors to combat the burden of cardiovascular disease, as they have been shown to lower the death rate of noncommunicable diseases, especially cardiovascular disease [6].

Consistent physical exercise has several advantages, especially in terms of recent and long-term health. Physical exercise will minimize the risk of premature death, heart disease, metabolic syndrome, cancer, and depression and improve sleep quality, according to the Ministry of Health Malaysia's recommendations [7]. Regular physical exercise, as well as physical health, can influence blood sugar levels, blood pressure levels, weight, and lipid levels in the body $[8,9]$. Individuals who participate in regular walking routines and strength training effectively lowered their waist circumference dimensions and overall body weight [10].

Nonetheless, many women today, especially housewives and retirees, lead sedentary lifestyles that lead to physical inactivity [11-13]. Housewives' duties have been said to discourage them from participating in prescribed physical activity, as they are busy managing the household and taking care of the children [14]. This puts this demographic segment at a greater risk of developing a condition as a result of long-term physical inactivity, such as cardiovascular disease.

Due to their hectic schedules and lack of physical exercise, those who live in metropolitan areas and have a low income are at a higher risk of acquiring cardiovascular illnesses [4]. Moderate physical exercise can help to minimize or eliminate the chance of acquiring the condition [10]. The Ministry of Health Malaysia recommends that individuals aged from 16 to 64 engage in moderate physical activity for $150 \mathrm{~min}$ per week or $75 \mathrm{~min}$ per week at high intensity. However, housewives often do not have time to engage in the recommended amount of physical exercise [6]. Because there is a lack of information on housewives with low income in Malaysia, this study is important to provide additional information about this group.

Previous research has concentrated on blue-collar employees, office workers, students, and teachers, but there has been little research on housewives, especially in Malaysia. Blue-collar employees [15], office workers [16], and students [17] have been shown to be more likely to exhibit cardiovascular risk factors due to unhealthy lifestyles such as lack of physical activity and unhealthy diet, while teachers have a better lifestyle and therefore showing lesser cardiovascular risk factors [18]. Therefore, the aim of this study was to assess if there is a relationship between physical activity and cardiovascular risk factors among housewives in the low-cost housing provision in Kuala Lumpur.

\section{Materials and Methods}

This cross-sectional study was conducted in the low-cost housing provision located in metropolitan Kuala Lumpur. The subjects were housewives who met the inclusion criteria and voluntarily participated. Subjects who were disabled or had a chronic disease, pregnant, and had a history of cardiovascular disease were excluded from this study.

This study was approved by the Universiti Kebangsaan Malaysia Research Ethics Committee. A self-administered and guided questionnaire consisting of the sociodemographic background of age, duration of being a housewife, number of children, education level, and household income, as well as the International Physical Activity Questionnaire (IPAQ)-short form, was distributed to the suitable housewives. Subjects who agreed to participate in the study signed a form confirming informed consent.

Physical activity was assessed by using the International Physical Activity Questionnaire (IPAQ)-short form through an interview session. The questionnaire was tested and validated for its reliability among the Malay population in Malaysia by another researcher [19]. This component consists of 7 questions regarding the physical activity 
performed during the last 7 days, which include vigorous-intensity and moderate-intensity physical activity, walking, and sitting. Details on the length of time spent performing physical activities on both weekdays and weekends were acquired during the interview session. Physical activity was scored by using the following formula:

\section{MET-min/week $=$ min of activity $/$ day $\times$ day per week $\times$ MET level}

The level of physical activity was classified into three categories, which are low (<600 MET-minutes/week), moderate (600-3000 MET-minutes/week), and high ( $\geq 3000$ MET-minutes/week) according to the guidelines of the IPAQ [20]. In order to determine moderate-to-vigorous physical activity, the total score of the IPAQ was applied, using the categories sedentary ( $\leq 100$ counts/min), light (101-1951 counts/min), moderate (1952-5724 counts/ $\mathrm{min}$ ), and vigorous ( $\geq 5725$ counts $/ \mathrm{min}$ ) [21].

Biomarkers of cardiovascular risk comprised indicators for overweight and obesity (body mass index, waist circumference), blood pressure, fasting blood glucose, and total cholesterol. Weight was measured using an analog scale to the nearest $0.1 \mathrm{~kg}$, without shoes, with light clothing, and items removed from the subjects' pockets before being weighed. Height was measured to the nearest $0.5 \mathrm{~cm}$ by using a portable height measuring device (Seca 213). Body mass index (BMI) was calculated as weight in kilograms divided by height in meters squared $\left(\mathrm{kg} \mathrm{m}^{-2}\right)$ and categorized according to cut-off points for Asian population, which are: which are underweight $(<18.5)$, normal (18.5-22.9), overweight (23.0-27.49), and obesity ( $\geq 27.5)$. Waist circumference (WC), an indicator of abdominal obesity, was taken at the midpoint between the top of the iliac crest and the lower margin of the last palpable midaxillary line at minimal respiration of the normal expiration. The data were analyzed by using cut-off points for Asian population ( $\geq 80 \mathrm{~cm}$ for women) [22]. Blood pressure (BP) was measured by using a digital sphygmomanometer (Omron Inc., Osaka, Japan) with a suitable cuff size with the subject seated and rested. Hypertension was defined as systolic blood pressure (SBP) of $\geq 140 \mathrm{mmHg}$, diastolic blood pressure (DBP) of $\geq 90 \mathrm{mmHg}$, or a combination of both. Fasting blood glucose (FBG) and total cholesterol (TC) were measured using finger-prick samples on portable meters. An FBG value between 3.9 and $5.5 \mathrm{mmol} / \mathrm{L}^{-1}$ was considered normal, as was a TC of $\leq 5.2 \mathrm{mmol} / \mathrm{L}^{-1}[23,24]$.

The sample size that was required for this study was 68 according to formulae by Cochran [25]: $n=\left(\mathrm{z}_{i \mathrm{~A} / 2}\right)^{2} p(1-p) / \Delta^{2} ; p=$ prevalence of diabetes, $17.5 \%$, according to the National Health Morbidity Survey in Malaysia (NHMS) [24]; $\mathrm{z}=1.96 ; \Delta=$ margin of error, $9 \%$. The inclusion criteria for this study were: (i) participant was a housewife with no permanent income from a job; (ii) participant was a housewife for at least 2 years. Data were analyzed by using the Statistical Package for the Social Sciences (IBM SPSS Statistics Version 23.0). All data were tested for normality. Two-way ANOVA, one-way ANOVA, the Mann-Whitney U test, and the Kruskal-Wallis $\mathrm{H}$ test were applied to test the significant mean differences between groups. The relationship between the response variable MVPA and the predictor variable was determined by using negative binomial regression.

\section{Results}

Table 1 shows the sociodemographic characteristics of the 63 subjects who participated in this study. The subjects were mostly aged between 51 and 60 years $(41.3 \%)$ and had been a housewife for over 20 years (44.4\%). The majority of the respondents had three to four children $(47.6 \%)$, did not possess a tertiary education, and had an estimated household income in the range of RM 1001 to RM $2000(46.0 \%)$.

Table 2 presents the distribution of cardiovascular risk factors for low-income housewives in Kuala Lumpur. For BMI, 58.7\% of housewives were indicated as obese, and $28.6 \%$ were overweight $(29.10 \pm 5.67)$. About $81.0 \%$ of housewives were obese, as the WC exceeded the normal range of $80 \mathrm{~cm}$, with an overall mean of $92.74 \pm 16.40$. Most housewives had normal BP, where $52.4 \%$ showed normal systolic blood pressure, and $33.3 \%$ were prehypertensive, with an overall mean of $122.90 \pm 19.05$, which indicates they were prehypertensive. Similarly, 50.8\% had normal diastolic blood pressure, and $28.6 \%$ showed 
prehypertension, with an overall mean indicating prehypertension of $81.04 \pm 10.43$. A total of $49.2 \%$ of housewives had normal FBG levels, and $31.7 \%$ were at prediabetic levels $(6.48 \pm 2.81)$. As for TC, a total of $92.1 \%$ of housewives had normal cholesterol levels, and $6.3 \%$ were at high border levels $(4.15 \pm 0.72)$.

Table 1. Sociodemographic characteristic of the housewives $(n=63)$.

\begin{tabular}{cc}
\hline Characteristics & $n \mathbf{( \% )}$ \\
\hline Age & \\
\hline $21-30$ & $4(6.3)$ \\
$31-40$ & $14(22.2)$ \\
$41-50$ & $19(30.2)$ \\
$51-60$ & $26(41.3)$ \\
\hline Duration of Being a Housewife (years) & \\
\hline$\leq 10$ & $26(41.3)$ \\
$11-20$ & $9(14.3)$ \\
$>20$ & $28(44.4)$ \\
\hline Number of Children & $10(15.9)$ \\
$\leq 2$ & $30(47.6)$ \\
\hline-4 & $23(36.5)$ \\
\hline Education Level & $9(14.3)$ \\
Primary & $11(17.5)$ \\
Lower secondary & $41(65.1)$ \\
Upper secondary & $2(3.1)$ \\
\hline Certificate and above & \\
\hline Household Income & $10(15.9)$ \\
\hline RM 1001-RM 2000 & $29(46.0)$ \\
\hline RM 2000 & $24(38.1)$ \\
\hline
\end{tabular}

Table 2. Distribution of CVD risk factors for housewives $(n=63)$.

\begin{tabular}{ccc}
\hline CVD Risk Factors & $\boldsymbol{n} \mathbf{( \% )}$ & Mean \pm SD \\
\hline BMI ${\mathbf{~ k g ~ m ~} \mathbf{~}^{-\mathbf{2}} \text { ) }}$ & & \\
\hline Underweight & $0(0)$ & $29.10 \pm 5.67$ \\
Normal & $8(12.7)$ & \\
Overweight & $18(28.6)$ & \\
Obesity & $37(58.7)$ & \\
\hline WC (cm) & & \\
\hline Normal $(\leq 80$ cm) & $12(19.0)$ & $122.90 \pm 19.05$ \\
Obesity (>80 cm) & $51(81.0)$ & \\
\hline Systolic Blood Pressure (mm Hg) & & \\
\hline Normal & $33(52.4)$ & \\
Prehypertension & $21(33.3)$ & \\
Hypertension stage I & $5(7.9)$ & \\
Hypertension stage II & $4(6.4)$ & \\
\hline Diastolic Blood Pressure (mm Hg) & & \\
\hline Normal & $32(50.8)$ & \\
Prehypertension & $18(28.6)$ & \\
Hypertension stage I & $10(15.9)$ & \\
Hypertension stage II & $3(4.7)$ & \\
\hline
\end{tabular}


Table 2. Cont.

\begin{tabular}{ccc}
\hline CVD Risk Factors & $\boldsymbol{n} \mathbf{( \% )}$ & Mean \pm SD \\
\hline FBG level (mmol L ${ }^{-1}$ ) & & \\
\hline Normal & $31(49.2)$ & $6.48 \pm 2.81$ \\
Prediabetes & $20(31.7)$ & \\
Diabetes & $12(19.1)$ & \\
\hline TC Level (mmol L & & \\
\hline Normal & & \\
Borderline high & $58(92.1)$ & \\
High & $4(6.3)$ & \\
\hline
\end{tabular}

Table 3 demonstrates the results of the mean difference between CVD risk factors, age group, and education level using two-way ANOVA. The data showed that there was no significant mean difference between BMI, WC, DBP, FBG, and TC with age group as the main factor. Despite that, SBP $(F=3.49, p<0.05)$ showed significant mean differences with age group. A post-hoc test was performed on these significant parameters and revealed that there is a significant mean difference between the age group of 21-40 years and the age group of $51-60$ years (mean difference $=-17.59, p=0.006$ ). Furthermore, there was no significant mean difference in BMI, WC, SBP, DBP, FBG, and TC with education level as the main factor $(p>0.05)$.

Furthermore, there were no significant mean differences between the CVD risk factor and family income in Table 4 ( $p>0.05)$.

Table 3. Mean and standard deviation differences between CVD risk factors, age group, and education level.

\begin{tabular}{|c|c|c|c|}
\hline \multirow{2}{*}{ Age Group A } & \multicolumn{3}{|c|}{ Mean \pm SD } \\
\hline & $21-40(n=18)$ & $41-50(n=19)$ & $51-60(n=26)$ \\
\hline BMI $\left(\mathrm{kg} \mathrm{m}^{-2}\right)$ & $28.28 \pm 6.37$ & $30.30 \pm 5.89$ & $28.79 \pm 5.13$ \\
\hline $\mathrm{WC}(\mathrm{cm})$ & $88.17 \pm 11.29$ & $95.35 \pm 23.66$ & $93.98 \pm 10.68$ \\
\hline SBP (mm Hg) & $112.14 \pm 11.29$ & $123.74 \pm 14.99$ & $129.73 \pm 22.78$ \\
\hline $\mathrm{DBP}(\mathrm{mm} \mathrm{Hg})$ & $76.19 \pm 9.14$ & $84.24 \pm 10.43$ & $82.06 \pm 10.44$ \\
\hline FBG level $\left(\mathrm{mmol} \mathrm{L}^{-1}\right)$ & $5.26 \pm 0.61$ & $7.00 \pm 3.08$ & $6.93 \pm 3.32$ \\
\hline \multirow[t]{2}{*}{ TC level $\left(\mathrm{mmol} \mathrm{L}^{-1}\right)$} & $3.98 \pm 0.59$ & $4.07 \pm 0.64$ & $4.33 \pm 0.82$ \\
\hline & \multicolumn{3}{|c|}{ Mean \pm SD } \\
\hline Education Level & $\begin{array}{l}\text { Primary and Lower Secondary } \\
\qquad(n=20)\end{array}$ & \multicolumn{2}{|c|}{$\begin{array}{l}\text { Upper Secondary and Above } \\
\qquad(n=43)\end{array}$} \\
\hline $\mathrm{BMI}\left(\mathrm{kg} \mathrm{m}^{-2}\right)$ & $28.09 \pm 5.30$ & \multicolumn{2}{|c|}{$29.57 \pm 5.83$} \\
\hline $\mathrm{WC}(\mathrm{cm})$ & $92.63 \pm 22.42$ & \multicolumn{2}{|c|}{$92.78 \pm 13.02$} \\
\hline SBP (mm Hg) & $122.05 \pm 18.62$ & \multicolumn{2}{|c|}{$123.29 \pm 19.45$} \\
\hline DBP $(\mathrm{mm} \mathrm{Hg})$ & $79.30 \pm 8.66$ & \multicolumn{2}{|c|}{$81.85 \pm 11.16$} \\
\hline FBG level $\left(\mathrm{mmol} \mathrm{L}^{-1}\right)$ & $6.32 \pm 2.47$ & \multicolumn{2}{|c|}{$6.54 \pm 2.97$} \\
\hline TC level $\left(\mathrm{mmol} \mathrm{L}^{-1}\right)$ & $4.19 \pm 0.99$ & \multicolumn{2}{|c|}{$4.13 \pm 0.55$} \\
\hline
\end{tabular}

According to Table 5, a total of 57 of the housewives had low physical activity, which accounted for $90.5 \%$. About four housewives showed moderate physical activity $(6.3 \%)$, followed by two housewives who had a high level of physical activity (3.2\%). The overall mean of total physical activity obtained from this study is $451.35 \pm 617.78$ MET-min/week, which indicates that the level of physical activity among housewives is low. For the mean of moderate-to-vigorous physical activity (MVPA), the data showed that housewives were physically inactive (70.48 $\pm 282.36 \mathrm{~min} /$ week) because they did not reach $150 \mathrm{~min} /$ week as recommended. The average sitting time of a housewife is $2.92 \pm 1.49 \mathrm{~h}$ a day. 
Table 4. Mean differences between CVD risk factors and household income.

\begin{tabular}{|c|c|c|c|c|c|}
\hline \multirow[b]{2}{*}{ CVD Risk Factor } & \multicolumn{5}{|l|}{ Mean \pm SD } \\
\hline & $\leq \mathrm{RM} 1000(n=10)$ & $\begin{array}{c}\text { RM 1001-RM } 2000 \\
(n=29)\end{array}$ & $>$ RM $2000(n=24)$ & $\mathbf{F}$ & $p$-Value \\
\hline $\mathrm{BMI}\left(\mathrm{kg} \mathrm{m}^{-2}\right)$ & $26.25 \pm 5.83$ & $29.59 \pm 5.55$ & $29.71 \pm 5.63$ & 1.54 & 0.22 \\
\hline $\mathrm{WC}(\mathrm{cm})$ & $86.24 \pm 8.20$ & $92.55 \pm 12.46$ & $95.67 \pm 21.96$ & 1.18 & 0.32 \\
\hline $\mathrm{SBP}(\mathrm{mm} \mathrm{Hg})$ & $120.35 \pm 17.23$ & $123.38 \pm 16.38$ & $123.38 \pm 23.06$ & 0.10 & 0.90 \\
\hline $\mathrm{DBP}(\mathrm{mm} \mathrm{Hg})$ & $77.20 \pm 8.35$ & $83.24 \pm 10.30$ & $79.98 \pm 11.09$ & 1.47 & 0.24 \\
\hline FBG level $\left(\mathrm{mmol} \mathrm{L}^{-1}\right)$ & $7.16 \pm 4.63$ & $6.50 \pm 2.67$ & $6.16 \pm 1.97$ & 0.44 & 0.67 \\
\hline TC level $\left(\mathrm{mmol} \mathrm{L}^{-1}\right)$ & $4.02 \pm 0.83$ & $4.04 \pm 0.54$ & $4.34 \pm 0.84$ & 1.35 & 0.27 \\
\hline
\end{tabular}

Table 5. Status of physical activity based on the IPAQ $(n=63)$.

\begin{tabular}{ccc}
\hline Parameter & $\boldsymbol{n} \mathbf{( \% )}$ & Mean \pm SD \\
\hline Category of Physical Activity Level & \\
\hline Low & $57(90.5)$ & - \\
Moderate & $4(6.3)$ & - \\
High & $2(3.2)$ & \\
\hline Physical Activity Level & & $451.35 \pm 617.78$ \\
Total physical activity level (MET-min/week) & - & $70.48 \pm 282.36$ \\
MVPA (MET-min/week) & - & $2.92 \pm 1.49$ \\
Sitting (h/day) & - &
\end{tabular}

Moreover, Table 6 presents the mean differences between physical activity level, age group, education level, and household income. Based on these analyses, the results indicate that there were no significant median differences between physical activity level; age group, $\mathrm{H}(2)=4.70$; education level, $\mathrm{U}=393$; and household income, $\mathrm{H}(2)=3.62(p>0.05)$. Figure 1 shows a scatter plot between SBP $(\mathrm{mm} / \mathrm{Hg})$ and BMI $\left(\mathrm{kg} / \mathrm{m}^{2}\right)$. There was a significant positive correlation with the correlation coefficient $r=0.284(p<0.05)$. Furthermore, there was a significant positive correlation between DBP $(\mathrm{mm} / \mathrm{Hg})$ and BMI $\left(\mathrm{kg} / \mathrm{m}^{2}\right)$, with $\mathrm{r}=0.784$ and $p<0.001$, as shown in Figure 2.

Table 6. Mean differences between physical activity level, age group, education level, and household income.

\begin{tabular}{|c|c|c|c|c|c|c|}
\hline \multirow{2}{*}{ Factors } & \multicolumn{6}{|c|}{ Physical Activity Level } \\
\hline & $n$ & Mean & Median & IQR & $\mathbf{H}$ & $p$-Value \\
\hline \multicolumn{7}{|l|}{ Age } \\
\hline $21-40$ & 18 & 452 & 347 & 260 & & \\
\hline $41-50$ & 19 & 604.05 & 297 & 396 & & \\
\hline$>50$ & 26 & 321.35 & 198 & 355 & $4.70^{\mathrm{a}}$ & $>0.05$ \\
\hline \multicolumn{7}{|l|}{ Education Level } \\
\hline Primary and lower secondary & 20 & 294.5 & 264 & 247 & & \\
\hline Upper secondary and others & 43 & 513.56 & 240 & 445 & $393.00^{\mathrm{b}}$ & $>0.05$ \\
\hline \multicolumn{7}{|l|}{ Household Income } \\
\hline$\leq \mathrm{RM} 1000$ & 10 & 250.90 & 214.50 & 334 & & \\
\hline $\mathrm{RM}$ 1001-2000 & 29 & 352.14 & 198.00 & 256 & & \\
\hline$>$ RM 2000 & 24 & 635.50 & 396.00 & 656 & $3.62^{\mathrm{a}}$ & $>0.05$ \\
\hline
\end{tabular}




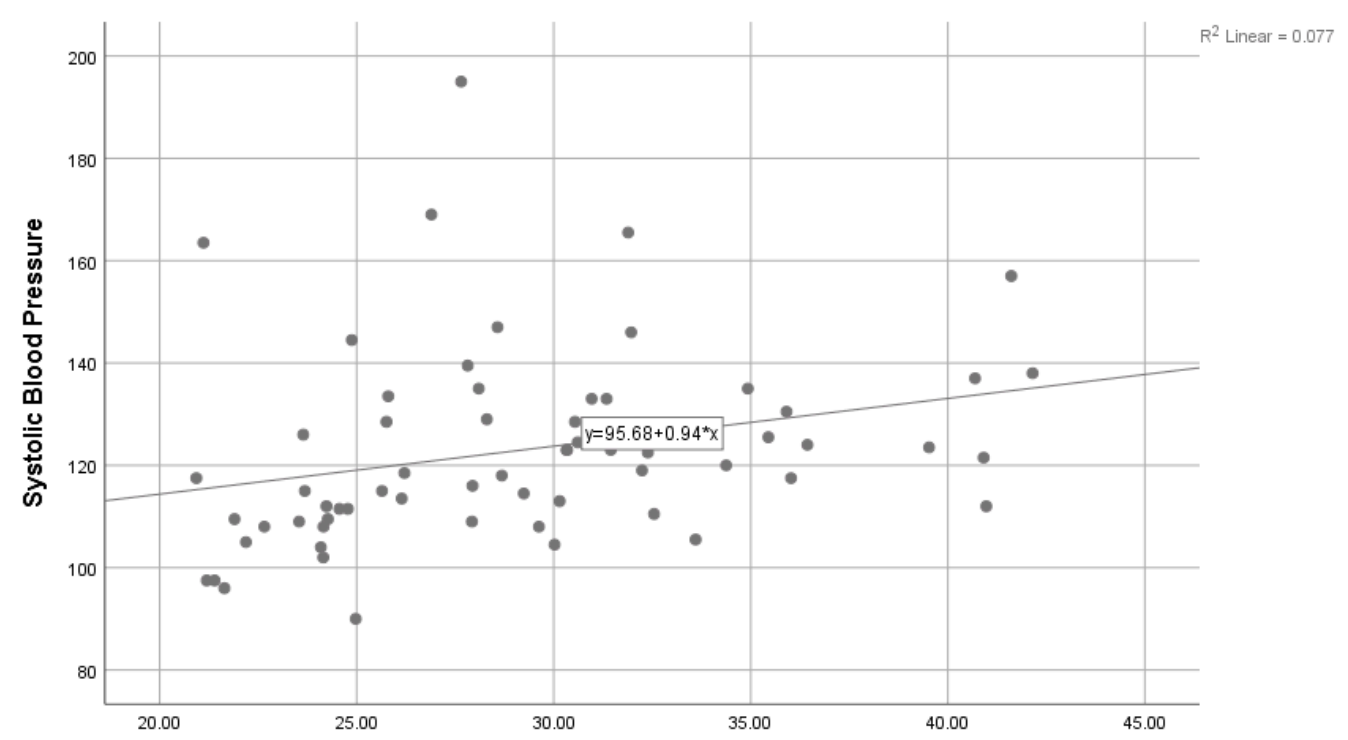

Figure 1. Correlation between SBP $(\mathrm{mm} / \mathrm{Hg})$ and BMI $\left(\mathrm{kg} / \mathrm{m}^{2}\right)$.

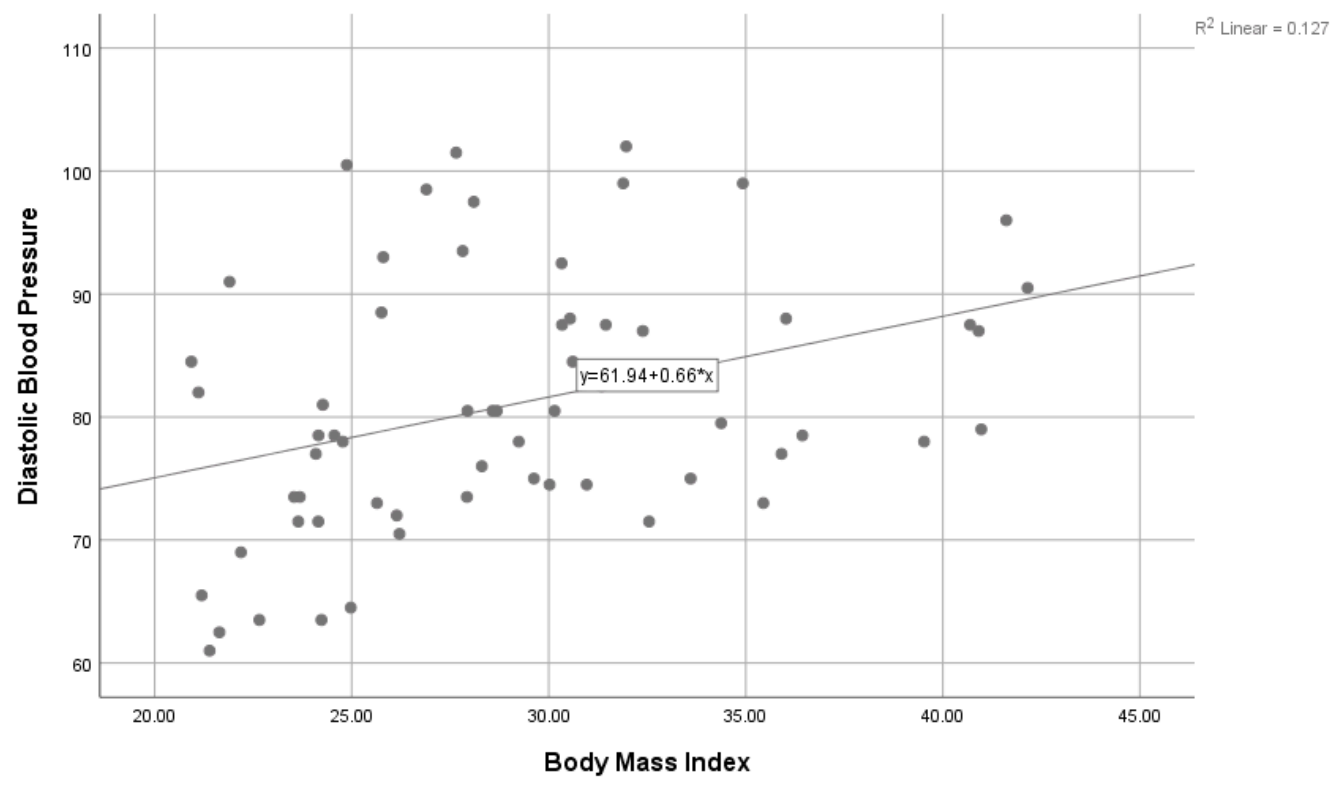

Figure 2. Correlation between DBP $(\mathrm{mm} / \mathrm{Hg})$ and BMI $\left(\mathrm{kg} / \mathrm{m}^{2}\right)$.

According to Table 7, negative binomial regression (NBR) was chosen because of the overdispersion in the data of MVPA. The standard deviation of MVPA was higher compared to the mean of MVPA in this study. Based on the likelihood ratio, Pearson's chi-squared test provided the overall model compared to the model without any predictors, showing that this model was significant $\left(\chi^{2}=90.06, p<0.001\right)$. Table 7 further presents the NBR coefficient for each predictor and standard errors. The variable FBG has a coefficient of $-0.570(p<0.001)$. This indicates for each one-unit increase in FBG, the expected log count of MVPA decreases by -0.57 . Furthermore, the variable TC has a coefficient of $-3.687(p<0.01)$. This indicates for each one-unit increase in TC, the MVPA decreases by -3.687 units. SBP and DBP were also statistically significant, with coefficients of 0.09 and -0.268 , respectively $(p<0.001)$. 
Table 7. Negative binomial regression between MVPA and predictors.

\begin{tabular}{cccccc}
\hline Parameter & Coefficients & Std Error & 95\% Confidence Interval & $p$-Value \\
\hline Intercept & 30.902 & 4.3320 & 22.412 & 39.393 & 0.000 \\
WC & 0.050 & 0.0737 & -0.094 & 0.195 & 0.495 \\
BMI & -0.092 & 0.1625 & -0.410 & 0.226 & 0.571 \\
FBG & -0.570 & 0.1360 & -0.836 & -0.303 & $<0001^{*}$ \\
TC & -3.687 & 0.5994 & -4.862 & -2.512 & $<0001^{*}$ \\
SBP & 0.090 & 0.0294 & 0.033 & 0.148 & 0.002 \\
DBP & -0.268 & 0.0489 & 22.412 & 39.393 & $<0001$ \\
\hline${ }^{*} p<0.001$. & & & &
\end{tabular}

\section{Discussion}

According to the findings of this study, housewives are more likely to be overweight or obese, which puts them at risk of cardiovascular disease. The incidence of overweight and obesity was found to be higher in this sample than in the NHMS 2015 (Malaysia [24]) and the World Health Organization [26], with prevalence rates of $54.4 \%$ and $52.0 \%$, respectively. The percentage of obesity in this study is parallel with the findings of NHMS 2015. Furthermore, the prevalence of obesity among women in Malaysia was somewhat higher than in Spain when comparing the NHMS population study (54.4\%) in 2015 with the Spanish population research in $2015(33.6 \%)$ [24,27]. The age range for adults in this research was 21 to 60, whereas the age range for NHMS 2019 was 18 to 64 [23]. As a result, there were minor differences in age groupings, which may have influenced the prevalence results. In addition, compared to other countries such as Spain (33\%) [27] and Indonesia $(28 \%)$, the respondents of this study recorded a high prevalence of obesity in the abdominal region, also known as abdominal obesity, which is measured by waist circumference [28]. As a result, more proactive advertising to raise awareness, particularly among Malaysian women, is needed to address these issues [15,23].

As a result, BMI and blood pressure rise in parallel with age, raising the risk of cardiovascular disease. Another study found that BMI, waist circumference, blood pressure, fasting glucose levels, triglycerides, low-density lipoprotein (LDL), and the ratio of total cholesterol to high-density lipoprotein (HDL) increase with age [29]. Similarly, a study in Kathmandu, Nepal, discovered that the prevalence of overweight or obese, as well as the prevalence of hypertension, increased with age until the age of 50 to 59 years [11]. These results are also consistent with the findings of the authors of [30], who found that people in their 50s and 60s had the greatest incidence of hypertension. This suggests a rise in cardiovascular risk as a result of age-related causes.

Low socioeconomic status, which includes schooling, income, and jobs, is often linked to poor health [4,31-33]. Adults in Sabah with lower levels of education are more likely to have hypertension and hypercholesterolemia, according to a study in 2019 [31]. Additionally, people who have a lower household income and have never been diagnosed with noncommunicable disorders have slightly higher systolic blood pressure, overall cholesterol, LDL cholesterol, and fasting blood glucose. This may be attributed to a lack of understanding about the benefits of routine check-ups. This is reinforced by the finding that women with a lower education level have a slightly higher incidence of cardiovascular risk factors [4]. This is due to a lack of accessibility and comprehension of health statistics. Women with a lower education level are often more likely to be ignorant of healthy lifestyle habits. Analysis of 882 Malaysians found that people with no educational qualifications and an income of less than RM 1000 are more likely to have a higher likehood of cardiovascular incidence in the next ten years [32]. However, the data of this study found that there is no significant difference between the factors of individual education level and household income with cardiovascular risk factors.

The majority of the participants in this sample had low levels of physical exercise, supplemented by moderate and high levels. This study's low prevalence of physical activity is higher than those seen in Somaliland (78.4\%) [29], Kathmandu (61.1\%) [11], 
Bolivia (64.77\%) [33], and Iran (52.2\%) [34]. Previous Malaysian surveys, on the other hand, have found reverse findings, with the bulk of respondents $(81.9 \%)$ being physically involved. In a previous study, there was a significant association between physical activity level and BMI [35]. In this paper, housewives spent the bulk of their time doing moderateintensity physical exercise, averaging $70.48 \pm 282.36$ MET-min a week. This illustrates that their amount of physical exercise is inadequate, as it falls short of the $150 \mathrm{~min}$ a week recommended by the Malaysian Ministry of Health Malaysia [6] and the World Health Organization (WHO) [3]. This may be attributed to a lack of time for housewives to engage in physical activity due to their responsibilities as housewives, as well as a lack of desire and motivation.

Furthermore, the results of this research indicate that there is no major association between physical activity levels and age, schooling, or income. Physical activity levels in the high-income community and highly educated individuals are observed to decline with rising age $[12,36,37]$. Bad health, such as heart, knee or back issues, arthritis, lack of a companion to perform physical exercise with, lack of interest in recreation, fear of falling, and pain, are typical obstacles to physical activity in older adults, according to previous studies $[38,39]$. Furthermore, people with lower levels of education and income are more likely to work in physically demanding occupations, resulting in higher levels of physical activity [40]. However, there is a connection between elevated levels of physical activity and high socioeconomic status in developed countries [41,42]. Individuals with a higher socioeconomic status have a greater awareness of the health benefits of physical exercise, especially recreational activities, and can therefore participate in more physical activity even when they are not employed [40].

In this research, there was only a significant relationship between physical exercise and cardiovascular risk. According to a previous study, some metabolic risk factors and physical activity groups have a statistically important negative association [43]. Furthermore, there is no connection between inactivity and overweight or obese in Malaysian men and women $[9,44,45]$. Except for triglyceride levels, a previous study observed little difference in the impact of physical exercise on glucose levels and lipid profile. In contrast, other studies in Malaysia found no significant relationship between physical exercise and cardiovascular risk factors in their studies $[14,46]$. This may be because other considerations such as calorie consumption, number of cigarettes smoked a day, and chronic stress are not taken into account [47]. Nonetheless, another study found a strong negative relationship between physical activity and overall cholesterol and total triglycerides, which is consistent with the results of this study [48]. Cardiorespiratory exercise exercises have a clear inverse association with metabolic syndrome, with waist circumference becoming the most significant factor [49].

There are several limitations in this study, such as the small sample size and the location of the study, which was limited to the Kuala Lumpur area. Therefore, the findings cannot be generalized beyond this particular group. Additionally, the study was conducted among housewives living in high-rise residential buildings, which also may have influenced their levels of physical activity, as opposed to living in ground-level housing. With regard to measurement of physical activity levels using self-reported methods, we do not deny that there is a tendency for subjects to overestimate their physical activity, especially when it comes to reporting moderate-to-vigorous physical activity. Thus, we highly recommend the usage of objective measurements of physical activity such as pedometry or accelerometry in future studies. In addition, this study also lacks the measurement of LDL and HDL cholesterol, as well as triglycerides as cardiovascular risk markers. However, as a majority of the sample showed normal cholesterol levels, it can be reasonable to assume that the LDL levels may well be within normal limits. Nevertheless, information on HDL may prove to be useful for future studies to observe how physical activity levels may affect HDL levels in this particular group. 


\section{Conclusions}

In conclusion, the majority of housewives in this study are physically inactive and are at risk of cardiovascular disease, as the majority of the sample is obese or overweight. Furthermore, low levels of MVPA are associated with increased cardiovascular risk factors among low-income housewives in Kuala Lumpur. Lifestyle-enhancing intervention programs may serve as a functional avenue to motivate low-income housewives to engage in physical activity and healthy behaviors to improve their cardiovascular risk factors and, ultimately, their quality of life.

Author Contributions: Conceptualization, N.Z.M.S.; methodology, N.Z.M.S. and N.M.F.F; formal analysis, S.A.H.; validation, H.M.A. and H.H.; investigation, N.Z.M.S. and N.S.S.; formal analysis, N.Z.M.S., S.A.H., and H.H.; data curation, S.A.H. and H.M.A.; writing-review and editing, N.Z.M.S. and N.S.S.; supervision, N.Z.M.S. and N.M.F.F.; project administration, N.Z.M.S. and N.M.F.F.; funding acquisition, N.Z.M.S., S.A.H., H.M.A., and H.H. All authors have read and agreed to the published version of the manuscript.

Funding: The APC was funded by grant GGP-2020-024 and Faculty of Health Sciences, Universiti Kebangsaan Malaysia.

Institutional Review Board Statement: The study was conducted according to the guidelines of the Declaration of Helsinki and approved by the Universiti Kebangsaan Ethical Approval Committee (Approval Number: JEP-2019-825).

Informed Consent Statement: All of the participants in the sample gave their informed consent.

Data Availability Statement: The corresponding author will provide the data used in this analysis upon request.

Acknowledgments: The writers are grateful to all of the participants who volunteered to take part in the research. The authors would like to express their gratitude to Dewan Bandaraya Kuala Lumpur for their cooperation, as well as Ahmad Faidsal Omar Al-Ahmadi and Thanes Balakrishna for their support of this study. The authors would like to express their gratitude to Universiti Kebangsaan Malaysia (UKM) (GGP-2020-024) and the Faculty of Health Sciences for their financial assistance in the publication.

Conflicts of Interest: The authors declare no conflict of interest.

\section{References}

1. Mensah, G.A.; Roth, G.A.; Fuster, V. The global burden of cardiovascular diseases and risk factors: 2020 and beyond. J. Am. Coll. Cardiol. 2019, 74, 2529-2532. [CrossRef] [PubMed]

2. World Health Organization. Cardiovascular Diseases (CVDs). 2017. Available online: https://www.who.int/news-room/factsheets / detail/cardiovascular-diseases-(cvds) (accessed on 23 September 2019).

3. World Health Organization. Noncommunicable Diseases (NCD) Country Profiles. 2018. Available online: https://www.who.int/ nmh/countries/mys_en.pdf (accessed on 11 December 2019).

4. $\quad$ Ghazali, S.M.; Seman, Z.; Cheong, K.C.; Hock, L.K.; Manickam, M.; Kuay, L.K.; Yusoff, A.F.; Mustafa, F.I.; Mustafa, A.N. Sociodemographic factors associated with multiple cardiovascular risk factors among Malaysian adults. BMC Public Health 2015, 15, 68. [CrossRef] [PubMed]

5. Mohammadnezhad, M.; Mangum, T.; May, W.; Lucas, J.J.; Ailson, S. Common modifiable and non-modifiable risk factors of cardiovascular disease (CVD) among Pacific countries. World J. Cardiovasc. Surg. 2016, 6, 153-170. [CrossRef]

6. Bahagian Pendidikan Kesihatan, Kementerian Kesihatan Malaysia. Garis Panduan Aktiviti Fizikal Malaysia. 2017. Available online: https:/ / mdes.org.my/wp-content/uploads/2017/07/garis-panduan-aktiviti-fizikal-2017.pdf (accessed on 10 October 2019).

7. Kim, H.C.; Oh, S.M. Noncommunicable diseases: Current status of major modifiable risk factors in Korea. J. Prev. Med. Public Health 2013, 46, 165-172. [CrossRef] [PubMed]

8. Colberg, S.R.; Sigal, R.J.; Yardley, J.E.; Riddell, M.C.; Dunstan, D.W.; Dempsey, P.C.; Horton, E.S.; Castorino, K.; Tate, D.F. Physical activity/exercise and diabetes: A position statement of the American Diabetes Association. Diabetes Care 2016, 39, $2065-2079$. [CrossRef] [PubMed]

9. Chan, Y.Y.; Lim, K.K.; Lim, K.H.; Teh, C.H.; Kee, C.C.; Cheong, S.M.; Khoo, Y.Y.; Baharudin, A.; Ling, M.Y.; Omar, M.A.; et al. Physical activity and overweight/obesity among Malaysian adults: Findings from the 2015 National Health and morbidity survey (NHMS). BMC Public Health 2017, 17, 733. [CrossRef]

10. Hornbuckle, L.M.; Liu, P.Y.; Ilich, J.Z.; Kim, J.S.; Arjmandi, B.H.; Panton, L.B. Effects of resistance training and walking on cardiovascular disease risk in African-American women. Med. Sci. Sports Exerc. 2012, 44, 525-533. [CrossRef] 
11. Anil, O.M.; Yadav, R.S.; Shrestha, N.; Koirala, S.; Shrestha, S.; Nikhil, O.M.; Baidar, M.; Chaudhary, N.; Jaishwal, C.; Yadav, N.S.; et al. Prevalence of cardiovascular risk factors in apparently healthy urban adult population of Kathmandu. J. Nepal Health Res. Counc. 2019, 16, 438-445. [CrossRef] [PubMed]

12. Moniruzzaman, M.; Ahmed, M.M.; Zaman, M.M. Physical activity levels and associated socio-demographic factors in Bangladeshi adults: A cross-sectional study. BMC Public Health 2017, 17, 59. [CrossRef]

13. Najafipour, H.; Moazenzadeh, M.; Afshari, M.; Nasri, H.R.; Khaksari, M.; Forood, A.; Mirzazadeh, A. The prevalence of low physical activity in an urban population and its relationship with other cardiovascular risk factors: Findings of a community-based study (KERCADRS) in southeast of Iran. ARYA Atheroscler. 2016, 12, 212-219.

14. Omar, A.; Husain, M.N.; Jamil, A.T.; Mohamad Nor, N.S.; Ambak, R.; Fazliana, M.; Ahamad Zamri, N.L.; Aris, T. Effect of physical activity on fasting blood glucose and lipid profile among low income housewives in the MyBFF@ home study. BMC Women's Health 2018, 18, 79-98. [CrossRef]

15. Prihartono, N.A.; Fitriyani, F.; Riyadina, W. Cardiovascular disease risk factors among blue and white-collar workers in Indonesia. Acta Med. Indones. 2018, 50, 96-103. [PubMed]

16. Nakhaie, M.R.; Koor, B.E.; Salehi, S.O.; Karimpour, F. Prediction of cardiovascular disease risk using framingham risk score among office workers, Iran, 2017. Saudi J. Kidney Dis. Transpl. 2018, 29, 608-614.

17. Martínez, S.M.A.; Leiva, O.A.M.; Sotomayor, C.C.; Victoriano, R.T.; Von Chrismar, P.A.M.; Pineda, B.S. Cardiovascular risk factors among university students. Rev. Med. Chil. 2012, 140, 426-435.

18. Scheuch, K.; Haufe, E.; Seibt, R. Teachers' health. Dtsch. Ärzteblatt Int. 2015, 112, 347-356. [CrossRef] [PubMed]

19. Chu, A.H.Y.; Moy, F.M. Reliability and validity of the Malay International Physical Activity Questionnaire (IPAQ-M) among a Malay population in Malaysia. Asia Pac. J. Public Health 2015, 27, NP2381-NP2389. [CrossRef] [PubMed]

20. IPAQ. Guidelines for Data Processing and Analysis of the International Physical Activity Questionnaire (IPAQ)—Short and Long Forms, Revised on November 2005. 2005. Available online: https:/ /docs.google.com/viewer?a=v\&pid=sites\&srcid= ZGVmYXVsdGRvbWFpbnxaGVpcGFxfGd4OjE0NDgxMDk3NDU1YWR1ZTM (accessed on 15 October 2019).

21. Craig, E.; Bland, R.; Reilly, J. Objectively measured physical activity levels of children and adolescents in rural South Africa: High volume of physical activity at low intensity. Appl. Physiol. Nutr. Metab. 2013, 38, 81-84. [CrossRef]

22. IDF. The IDF Consensuses Worldwide Definition of The Metabolic Syndrome; International Diabetes Federation: Brussels, Belgium, 2006.

23. Institute for Public Health. National Health and Morbidity Survey (NHMS) 2019: Vol. I: NCDs-Non-Communicable Diseases: Risk Factors and Other Health Problems; Institute for Public Health: Kuala Lumpur, Malaysia, 2019.

24. Institute for Public Health. National Health and Morbidity Survey NHMS. Summary on NHMS Report on Disease Prevalence; National Health and Morbidity Survey: Kuala Lumpur, Malaysia, 2015.

25. Cochran, W.G. Sampling Techniques, 2nd ed.; John Wiley and Sons, Inc.: New York, NY, USA, 1963.

26. WHO. Obesity and Overweight; World Health Organization: Geneva, Switzerland, 2020; Available online: https://www.who.int/ news-room/fact-sheets/detail/obesity-and-overweight (accessed on 11 December 2019).

27. Aranceta-Bartrina, J.; Pérez-Rodrigo, C.; Alberdi-Aresti, G.; Ramos-Carrera, N.; Lázaro-Masedo, S. Prevalence of general obesity and abdominal obesity in the Spanish adult population (aged 25-64 years) 2014-2015: The ENPE study. Rev. Española Cardiol. 2016, 69, 579-587. [CrossRef]

28. Harbuwono, D.S.; Pramono, L.A.; Yunir, E.; Subekti, I. Obesity and central obesity in Indonesia: Evidence from a national health survey. Med. J. Indones. 2018, 27, 114-120. [CrossRef]

29. Ahmad, N.; Adam, S.I.; Nawi, A.M.; Hassan, M.R.; Ghazi, H.F. Abdominal obesity indicators: Waist circumference or waist-to-hip ratio in Malaysian adults population. Int. J. Prev. Med. 2016, 7, 82.

30. Amiri, M.; Majid, H.A.; Hairi, F.; Thangiah, N.; Bulgiba, A.; Su, T.T. Prevalence and determinants of cardiovascular disease risk factors among the residents of urban community housing projects in Malaysia. BMC Public Health 2014, 14, S3. [CrossRef]

31. Harris, H.; Ooi, Y.B.; Lee, J.S.; Matanjun, P. Non-communicable diseases among low income adults in rural coastal communities in Eastern Sabah, Malaysia. BMC Public Health 2019, 19, 554. [CrossRef]

32. Su, T.T.; Amiri, M.; Mohd Hairi, F.; Thangiah, N.; Bulgiba, A.; Majid, H.A. Prediction of cardiovascular disease risk among low-income urban dwellers in metropolitan Kuala Lumpur, Malaysia. Biomed. Res. Int. 2015, 2015, 516984. [CrossRef] [PubMed]

33. Mamani-Ortiz, Y.; San Sebastián, M.; Armaza, A.X.; Luizaga, J.M.; Illanes, D.E.; Ferrel, M.; Mosquera, P.A. Prevalence and determinants of cardiovascular disease risk factors using the WHO STEPS approach in Cochabamba, Bolivia. BMC Public Health 2019, 19, 786. [CrossRef]

34. Mirzaei, M.; Mirzaei, M.; Sarsangi, A.R.; Bagheri, N. Prevalence of modifiable cardiovascular risk factors in Yazd inner-city municipalities. BMC Public Health 2020, 20, 134. [CrossRef]

35. Aisyah Waheeda, R.; Rheshara, S.; Nik Nasreen, N.K.; Sabariah, A.H. Physical Activity Status of Community in Kg Hulu Chuchoh, Sungai Pelek, Sepang, Selangor, Malaysia. Int. Educ. Res. J. 2018, 6, 37-46.

36. Cheah, Y.K.; Poh, B.K. The determinants of participation in physical activity in Malaysia. Osong Public Health Res. Perspect. 2014, 5, 20-27. [CrossRef] [PubMed]

37. The, C.H.; Lim, K.K.; Chan, Y.Y.; Lim, K.H.; Azahadi, O.; Akmar, A.H.; Nadiah, Y.U.; Syafinaz, M.S.; Kee, C.C.; Yeo, P.S.; et al. The prevalence of physical activity and its associated factors among Malaysian adults: Findings from the National Health and Morbidity Survey 2011. Public Health 2014, 128, 416-423. 
38. Moschny, A.; Platen, P.; Klaaßen-Mielke, R.; Trampisch, U.; Hinrichs, T. Barriers to physical activity in older adults in Germany: A cross-sectional study. Int. J. Behav. Nutr. Phys. Act. 2011, 8, 121. [CrossRef] [PubMed]

39. Mathews, A.E.; Laditka, S.B.; Laditka, J.N.; Wilcox, S.; Corwin, S.J.; Liu, R.; Friedman, D.B.; Hunter, R.; Tseng, W.; Logsdon, R.G. Older adults' perceived physical activity enablers and barriers: A multicultural perspective. J. Aging Phys. Act. 2010, 18, 119-140. [CrossRef]

40. Jurakić, D.; Pedišić, Ž.; Andrijašević, M. Physical Activity of Croatian Population: Cross-Sectional Study Using International Physical Activity Questionnaire. Croat. Med. J. 2009, 50, 165-173. [CrossRef] [PubMed]

41. Beenackers, M.A.; Kamphuis, C.B.; Giskes, K.; Brug, J.; Kunst, A.E.; Burdorf, A.; Van Lenthe, F.J. Socioeconomic inequalities in occupational, leisure-time, and transport related physical activity among European adults: A systematic review. Int. J. Behav. Nutr. Phys. Act. 2012, 9, 116. [CrossRef]

42. Kari, J.T.; Pehkonen, J.; Hirvensalo, M.; Yang, X.; Hutri-Kähönen, N.; Raitakari, O.T.; Tammelin, T.H. Income and physical activity among adults: Evidence from self-reported and pedometer-based physical activity measurements. PLoS ONE 2015, 10, e0135651. [CrossRef]

43. Chu, A.H.; Moy, F.M. Association between physical activity and metabolic syndrome among Malay adults in a developing country, Malaysia. J. Sci. Med. Sport 2014, 17, 195-200. [CrossRef]

44. Jamil, A.T.; Ismail, A.; Idris, I.B.; Soo, K.C.; Teng, A.J.; Bahaman, N.A.; Fadzil, M.F. Levels of physical activity and its associated factors among health care workers. Malays. J. Public Health Med. 2016, 16, 127-133.

45. Saat, N.Z.M.; Nor Farah, M.F.; Hanawi, S.A.; Mohd Radhi, S. The associations between daily steps and cardiovascular risk factors among female teachers. Malays J. Mov. Health Exerc. 2020, 9, 113.

46. Zulkepli, Z.; Saat, N.Z.M.; Nor Farah, M.F.; Hanawi, S.A.; Zin, N.M. Relationship between physical activity level and cardiovascular risk factors among teachers. Asian J. Epidemiol. 2019, 12, 1-8. [CrossRef]

47. Abdullah, M.; Saat, N.Z.M.; Nor Farah, M.F.; Hui, C.Y.; Kamaralzaman, S. Association between Walking and Cardiovascular Risk Factors in University Employees. J. Med. Sci. 2015, 15, 105. [CrossRef]

48. Pang, Y.; Kartsonaki, C.; Du, H.; Millwood, I.Y.; Guo, Y.; Chen, Y.; Bian, Z.; Yang, L.; Walters, R.; Bragg, F.; et al. Physical activity, sedentary leisure time, circulating metabolic markers, and risk of major vascular diseases. Circ. Genom. Precis. Med. 2019, 12, e002527. [CrossRef]

49. Earnest, C.P.; Artero, E.G.; Sui, X.; Lee, D.C.; Church, T.S.; Blair, S.N. Maximal estimated cardiorespiratory fitness, cardiometabolic risk factors, and metabolic syndrome in the aerobics center longitudinal study. In Mayo Clinic Proceedings; Elsevier: Amsterdam, The Netherlands, 2013; Volume 88, pp. 259-270. 